Tohoku J. exp. Med., 1972, 106, 83-87

\title{
Influence of X-Irradiation of the Adrenal Gland on Corticoid Secretory Activity in Dogs
}

\author{
Keishun Nakasone \\ Department of Pathophysiology, * Atomic Disease Institute, \\ Nagasaki University School of Medicine, Nagasaki
}

\begin{abstract}
NaKasone, K. Influence of X-Irradiation of the Adrenal Gland on Corticoid Secretory Activity in Dogs. Tohoku J. exp. Med., 1972, 106 (1), 83-87 Adrenocortical activity in the dog was studied during the first 4 hours after $X$ irradiation of the adrenal with doses of 200-2,000 R. Under anesthetized conditions, the secretory activity was determined by measuring 11-hydroxycorticosteroids in the adrenal venous blood. The adrenocortical activity was found to be stimulated by localized X-irradiation of $800-2,000 \mathrm{R}$ to the adrenal, the response being roughly proportional to the dose. However, with hypophysectomized dogs, the adrenocortical secretory response to $\mathrm{X}$-irradiation of the adrenal was entirely absent, probably as a result of hypophysectomy. These results suggest that the $\mathrm{X}$-irradiation doses of $800-2,000 \mathrm{R}$ in the present study, if delivered directly to the adrenal, produce an augmentation in the corticoid secretory activity and its action occurs through the pituitary-adrenocortical mechanism. X-irradiation of the adrenal; adrenal 11-hydroxycorticosteroid secretion; hypophysectomy; dog
\end{abstract}

There are few reports as to the effect of $\mathrm{X}$-irradiation of the adrenal gland on its corticoid secretory activity, although there are a great number of papers on the effect of whole body X-irradiation (Wexler, Penchary and Thomas 1952, Hochman and Bloch Frankenthal 1953, Wolf and Bowman 1964, Hameed and Haley 1964). Engelstad and Torgersen (1937), in their morphological study, showed that hemorrhages and degenerative changes occurred in the adrenal cortex after $\mathrm{X}$-irradiation of the adrenal with doses of 2,200-2,500 $\mathrm{R}$ in rabbits. Ungar, Rosenfeld, Dorfman and Pincus (1955), in experiments on exposure of the isolated, ACTHstimulated calf adrenal to gamma radiation $\left({ }^{60} \mathrm{Co}\right)$ during perfusion, observed a decreased secretion of hydrocortisone, corticosterone, and other unidentified PorterSilber chromogens. Shima and Matsuba (1963), who studied the secretory activity of the rat adrenal cortex under localized $\mathrm{X}$-irradiation, have demonstrated an increase in adrenocortical activity after irradiation of the adrenal with $800 \mathrm{R}$ and a decrease at doses more than 1,000 R. They considered, these might be due to direct irradiation effects.

The object of this work is to determine more precisely the effect of localized $\mathrm{X}$-irradiation on adrenocortical activity in dogs, and to evaluate the mechanism whereby the effect is produced.

Received for publication, June 19, 1971.

* Director: Prof. K. Yamashita. 


\section{Materials and Methods}

Mongrel adult dogs ranging in weight from 11.1 to $20.0 \mathrm{~kg}$ were used. Experiments were performed on intact and hypophysectomized dogs.

Lumboadrenal vein cannulation and $X$-irradiation. The dogs were anesthetized with sodium pentobarbital $(25 \mathrm{mg} / \mathrm{kg})$. By a modification of the lumbar route method of Satake, Sugawara and Watanabe (1927), the left adrenal gland was exposed and the left lumboadrenal vein cannulated. The dogs were allowed to recover during a period of approximately $18 \mathrm{hr}$ after which they were re-anesthetized with sodium pentobarbital. Two hr after the dogs had been re-anesthetized, two control samples of adrenal venous blood were collected. Then, $\mathrm{X}$-irradiation of the left adrenal area was made using doses of 200-2,000 R. The X-ray characteristics were $180 \mathrm{KVp}, 20 \mathrm{~mA}, 37 \mathrm{~cm}$ FSD and the HVT was $1.0 \mathrm{~mm} \mathrm{Cu}$. The dose-rate to the adrenal gland was $130 \mathrm{R} / \mathrm{min}$. Immediately after the external $\mathrm{X}$-irradiation, collection of adrenal venous blood was begun. And also samples of adrenal venous blood were collected intermittently during a period of 240 min. In addition, in the group of hypophysectomized dogs, the responsiveness to exogenous corticotrophin was examined by injection of ACTH (Organon) in a dose of $1 \mathrm{IU} / \mathrm{kg}$.

Analysis of blood samples from the lumboadrenal vein. Adrenal blood was obtained by collecting the total venous effluent of the left adrenal gland for a period of 30-60 sec. Plasma from each sample was analyzed for 11-hydroxycorticosteroids by the method of Silber, Busch and Oslapas (1958).

\section{Results}

\section{Experiments in intact dogs}

When the adrenal gland was exposed to external X-irradiation of $200 \mathrm{R}$, there was no detectable increase in adrenocortical activity in most cases that were the low corticoid secretory levels during the control period (one of these dogs showed a slight but distinct effect). These low levels persisted during the first $4 \mathrm{hr}$ after irradiation. However, in few cases in which the control corticoid secretory levels were relatively high, an appreciable decrease in the secretion of adrenal 11-hydroxycorticosteroids (11-OHCS) was observed within $60 \mathrm{~min}$ after irradiation but it was soon followed by a gradual return to pre-radiation levels. After exposure to $800 \mathrm{R}$, there was a transient increase in adrenal corticoid secretion, the peak of which was attained at $15 \mathrm{~min}$. Within $30 \mathrm{~min}$ after irradiation, it returned towards control values. Following irradiation of 1,000 R, a gradual and prolonged increase in adrenocortical secretory activity was found. The hypersecretion was maintained over a 4 hr period of observation. After irradiation of $2,000 \mathrm{R}$, with one exception there was a considerable increase in the secretion of adrenal corticoids. The maximum increase occurred within approximately $60 \mathrm{~min}$ after irradiation. Results of experiments in intact dogs are illustrated in Fig. 1.

\section{Experiments in hypophysectomized dogs}

In view of Tanigawa's observation (1967) that in dogs the responsiveness of the adrenal cortex to ACTH at $24 \mathrm{hr}$ after hypophysectomy was markedly reduced, an attempt was made to the study secretory response to ACTH at approximately $20 \mathrm{hr}$ after hypophysectomy. The results showed that the adrenocortical 


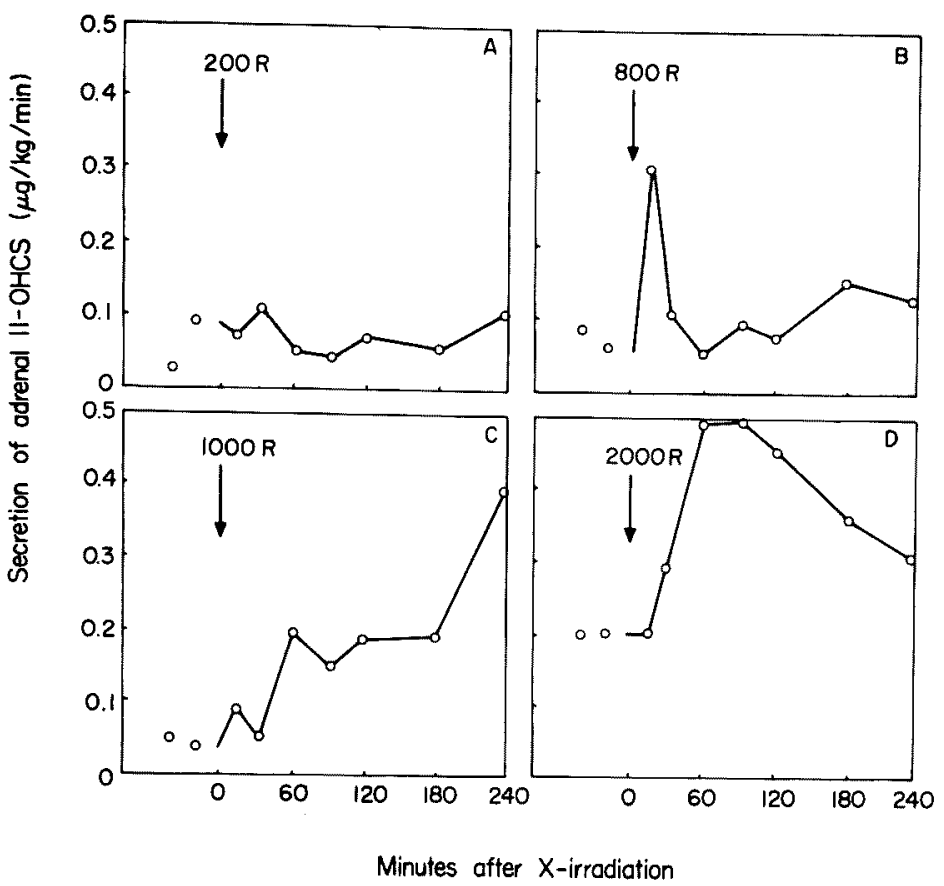

Fig. 1. Time course of secretion of adrenal 11-hydroxycorticosteroids (11-OHCS) after $\mathrm{X}$-irradiation of the adrenal gland in doses of $200-2,000 \mathrm{R}$ in intact dogs. Each point represents the mean in groups of 4-6 dogs: A, $200 \mathrm{R} ; \mathrm{B}, 800 \mathrm{R} ; \mathrm{C}, 1,000 \mathrm{R}$; and D, 2,000 R.

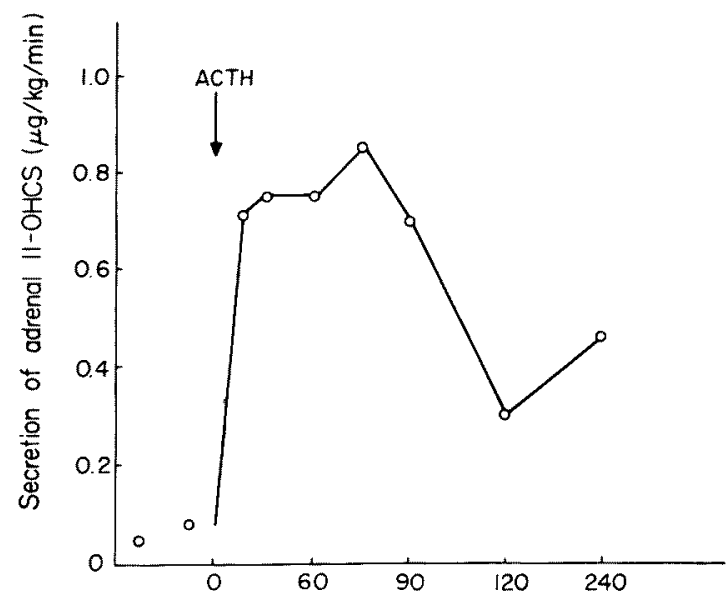

Minutes after $X$-irradiation

Fig. 2. The increased secretion of adrenal 11-hydroxycorticosteroids (11-OHCS) caused by an i.v. injection of ACTH (1 IU/ kg) approximately $20 \mathrm{hr}$ after hypophysectomy in dogs. Each point represents the mean in 3 dogs. 


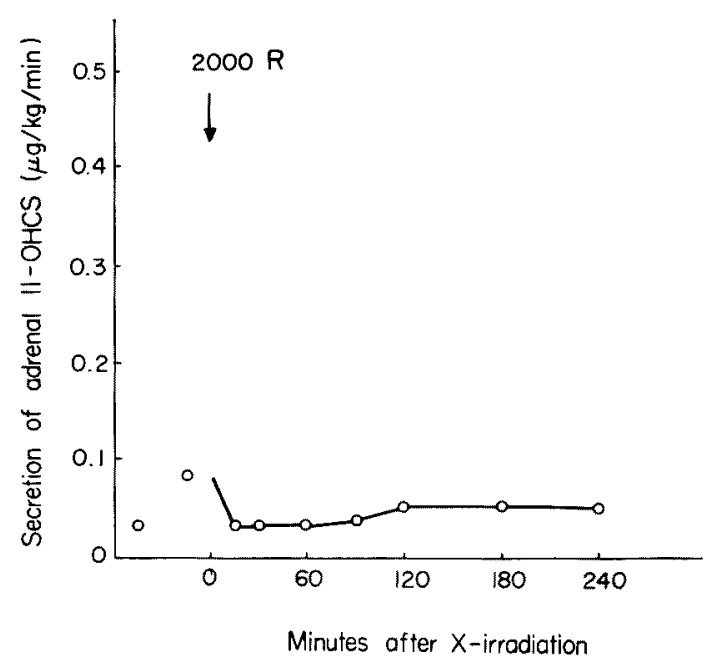

Fig. 3. Time course of secretion of 11-hydroxycorticosteroids (11-OHCS) by the canine adrenal after $\mathrm{X}$-irradiation of it with 2,000 $\mathrm{R}$ in hypophysectomized dogs. Hypophysectomy was performed at approximately $18 \mathrm{hrs}$ before $\mathrm{X}$-irradiation. Each point represents the mean in 3 dogs.

response was considerably high (Fig. 2). Therefore, the present experiments in hypophysectomized dogs were performed under this condition.

When the adrenal gland of hypophysectomized dog was irradiated with $2,000 \mathrm{R}$, no appreciable increase in adrenal corticoid secretion occurred during the $4 \mathrm{hr}$ period of observation (Fig. 3). At the end of these observations, ACTH (1 IU/ $\mathrm{kg}$ ) was injected intravenously and this was followed by a marked increase in the secretion of adrenal corticoids.

\section{Discussion}

The results in intact dogs indicate that $\mathrm{X}$-irradiation of the adrenal in doses up to $2,000 \mathrm{R}$ is accompanied by adrenocortical stimulation. These findings are in accord with the observation by of Shima and Matsuba (1963) with dose of $800 \mathrm{R}$ but are in disagreement with their results obtained at doses more than $1,000 \mathrm{R}$.

Although care was taken in the present experiments, to irradiate a limited field over the adrenal gland so that other tissues near the adrenal would not be included in this field, it appeared that the neighboring tissues might be, in part, affected by this treatment. It therefore seemed possible that the response occurred by a direct and/or an indirect effect of irradiation. However, studies with hypophysectomized dogs showed that the adrenocortical secretory response to irradiation was entirely absent, probably as a result of hypophysectomy. The effect of localized irradiation to the adrenal is thus assumed to be an indirect action through the pituitary-adrenocortical mechanism. Evidence for the adrenal cortex as the site of action has been obtained from experiments in vivo and in 
vitro. Using radiation doses which would produce $100 \%$ mortality within a few days in animals, Ungar, Rosenfeld, Dorfman and Pincus (1955) demonstrated that gamma irradiation of the isolated, ACTH-stimulated calf adrenal gland induced a significant decrease in its steroidogenic activity. Shima and Matsuba (1963) also indicated a direct inhibitory effect of X-rays on the rat adrenal cortex, from the observations that $\mathrm{X}$-irradiation of the adrenal in doses of $1,000-2,000$ $R$ caused a decrease of corticoid concentration in venous blood from the irradiated adrenal but not in venous blood from the contralateral non-irradiated adrenal. In the present study too, $\mathrm{X}$-irradiation had a depressing effect on adrenocortical activity even in doses of $200 \mathrm{R}$ when the experiments were performed under stressful conditions. Some differences in experimental design and species may be responsible for the divergent findings since their experiments were carried out on rats and in stress situations such as those brought about by a rapid operation under ether. In any way, the present results indicate that exposure of the adrenal gland to 200-2,000 $\mathrm{R}$ may have no direct inhibitory effect on adrenocortical secretion because a good responsiveness of the adrenal cortex to ACTH was obtained at $5 \mathrm{hrs}$ after $\mathrm{X}$-irradiation in hypophysectomized dogs.

\section{Acknowledgment}

I am indebted to Prof. K. Yamashita for his suggestion throughout the course of this investigation and his help in preparing this manuscript, and to Mr. K. Kawao for his assistance in the experiments.

\section{References}

1) Engelstad, R.B. \& Torgersen, O. (1937) Experimental investigations of the effects of roentgen rays on the suprarenal glands in rabbits. Acta radiol., 18, 671-687.

2) Hameed, J.M.A. \& Haley, T.J. (1964) Plasma and adrenal gland corticosterone levels after X-ray exposure in rats. Radiat. Res., 23, 620-629.

3) Hochman, A. \& Bloch Frankenthal, L.F. (1953) The effect of low and high X-ray dosage on the ascorbic acid content of the suprarenal. Brit. J. Radiol., 26, 599-600.

4) Sataké, Y., Sugawara, T. \& Watanabé, M. (1927) A method for collecting the blood from the suprarenal gland in the dog, without fastening, narcotizing, laparotomy or provoking any pain. Tohoku J. exp. Med., 8, 501-534.

5) Shima, S. \& Matsuba, M. (1963) Effects of X-irradiation on adrenal function in rats. J. physiol. Soc. Japan (Jap.), 25, 377-382.

6) Silber, R.H., Busch, R.D. \& Oslapas, R. (1958) Practical procedure for estimation of corticosterone or hydrocortisone. Clin. Chem., 4, 278-285.

7) Tanigawa, H. (1967) On the mechanism of stimulatory action of histamine upon the adrenal 17-hydroxycorticosteroid secretion in the dog. Tohoku J. exp. Med., 92, 281-289.

8) Ungar, F., Rosenfeld, G., Dorfman, R.I. \& Pincus, G. (1955) Irradiation and adrenal steroidogenesis: Influence of irradiation of isolated ACTH-stimulated calf adrenals on their cortical output. Endocrinology, 56, 30-36.

9) Wexler, B.C., Penchary, R. \& Thomas, S.E. (1952) Adrenal ascorbic acid in male and female rats after total body X-ray irradiation. Proc. Soc. exp. Biol. Med. (N.Y.), 79, 183-186.

10) Wolf, B.C. \& Bowman, R.E. (1964) Adrenal function in the rhesus monkey after total-body X-irradiation. Radiat. Res., 23, 232-238. 